\title{
Insights into deregulated TNF and IL-10 production in malaria: implications for understanding severe malarial anaemia
}

Philippe S Boeuf ${ }^{1}$, Séverine Loizon ${ }^{1,9,10}$, Gordon A Awandare², John KA Tetteh², Michael M Addae ${ }^{3}$, George O Adjei ${ }^{4}$, Bamenla Goka ${ }^{4}$, Jørgen AL Kurtzhals ${ }^{5,6,7,8}$, Odile Puijalon', Lars Hviid ${ }^{5,8}$,

Bartholomew D Akanmori ${ }^{2}$ and Charlotte Behr ${ }^{1,9,10^{*}}$

\begin{abstract}
Background: Severe malarial anaemia (SMA) is a major life-threatening complication of paediatric malaria. Protracted production of pro-inflammatory cytokines promoting erythrophagocytosis and depressing erythropoiesis is thought to play an important role in SMA, which is characterized by a high TNF/L-10 ratio. Whether this TNF/L-10 imbalance results from an intrinsic incapacity of SMA patients to produce IL-10 or from an IL-10 unresponsiveness to infection is unknown. Monocytes and T cells are recognized as the main sources of TNF and IL-10 in vivo, but little is known about the activation status of those cells in SMA patients.

Methods: The IL-10 and TNF production capacity and the activation phenotype of monocytes and T cells were compared in samples collected from 332 Ghanaian children with non-overlapping SMA $(n=108)$, cerebral malaria (CM) $(n=144)$ or uncomplicated malaria $(U M)(n=80)$ syndromes. Activation status of monocytes and T cells was ascertained by measuring HLA-DR ${ }^{+}$and/or $\mathrm{CD} 9^{+}$surface expression by flow cytometry. The TNF and IL-10 production was assessed in a whole-blood assay after or not stimulation with lipopolysaccharide (LPS) or phytohaemaglutinin (PHA) used as surrogate of unspecific monocyte and T cell stimulant. The number of circulating pigmented monocytes was also determined.
\end{abstract}

Results: Monocytes and T cells from SMA and CM patients showed similar activation profiles with a comparable decreased HLA-DR expression on monocytes and increased frequency of $\mathrm{CD}_{6} 9^{+}$and $\mathrm{HLA}-\mathrm{DR}{ }^{+} \mathrm{T}$ cells. In contrast, the acute-phase IL-10 production was markedly decreased in SMA compared to CM $(P=.003)$ and UM $(P=.004)$. Although in SMA the IL-10 response to LPS-stimulation was larger in amplitude than in CM $(P=.0082)$, the absolute levels of IL-10 reached were lower $(P=.013)$. Both the amplitude and levels of TNF produced in response to LPS-stimulation were larger in SMA than CM $(P=.019)$. In response to PHA-stimulation, absolute levels of IL-10 produced in SMA were lower than in CM $(P=.005)$ contrasting with TNF levels, which were higher $(P=.001)$.

Conclusions: These data reveal that SMA patients have the potential to mount efficient IL-10 responses and that the TNF/L-10 imbalance may reflect a specific monocyte and T cell programming/polarization pattern in response to infection.

Keywords: Malaria, Anaemia, Cerebral malaria, Severe malarial anaemia, Monocytes, T cells, CD69, HLA-DR, Monocyte de-activation, TNF, IL-10, Cytokines

\footnotetext{
* Correspondence: charlotte.behr@u-bordeaux2.fr

'Institut Pasteur, Unité d'Immunologie Moléculaire des Parasites URA CNRS

2581, Paris, France

9UMR CNRS 5164, Bordeaux, France

Full list of author information is available at the end of the article
} 


\section{Background}

In sub-Saharan Africa, severe malarial anaemia (SMA) is a frequent complication of Plasmodium falciparum infections in young children [1] and is one of the main causes of severe anaemia, with a case-fatality rate reaching 23\% in malaria holoendemic areas [2]. Pathogenesis of SMA is not well understood, although destruction of the infected erythrocytes accompanied by clearance of uninfected erythrocytes, erythropoietic suppression and dyserythropoiesis, can all contribute to anaemia $[3,4]$. SMA is associated with elevated levels of myelosuppressive cytokines, such as TNF, but this is not specific to the SMA syndrome, as children with cerebral malaria (CM) also have highly elevated TNF plasma levels [5]. Previous analysis showed that SMA can be distinguished from $\mathrm{CM}$ on the basis of an elevated ratio of TNF to its potent anti-inflammatory regulator IL-10 suggesting a central role for the TNF-IL-10 balance in SMA pathogenesis $[5,6]$. This is supported by the observation that anaemia is increased in IL-10 knockout mice infected with Plasmodium chabaudi [7] and reversed upon TNF neutralization $[7,8]$.

TNF alone and in concert with multiple other cytokines and chemokines is a potent inhibitor of haematopoietic stem cells [9]. Elevated levels of TNF in patients with chronic inflammation [10], aplastic anaemia [11] or inherited anaemic disorders [12] have been associated with inhibition of erythropoiesis. Multiple underlying mechanisms have been reported, including the caspasemediated cleavage of the major erythroid transcription factor GATA-1 [13], impairment of cell cycle progression [14], and remodelling of the extracellular matrix within erythroid niches [15]. The high TNF/IL-10 ratio characteristic of SMA patients might reflect an insufficient production of IL-10 in SMA patients to prevent or counteract the inhibition of erythropoiesis and the increase of erythrophagocytosis induced by TNF and/or to mitigate other pro-inflammatory stimuli.

Monocytes and $\mathrm{T}$ cells are generally recognized as the main source of TNF and IL-10 in vivo. However, little is known about their activation status and their contribution to the TNF/IL-10 imbalance associated with SMA. Data on monocyte or $\mathrm{T}$ cell status in SMA patients are scarce, although indirect lines of evidence suggest activation of the monocyte/macrophage compartment in SMA patients [16-19]. To date, no published study has compared $\mathrm{T}$ cell and monocyte status in SMA and CM.

The work reported here sought at investigating whether children with SMA or CM have distinct TNF and IL-10 production capacities accounting for their different TNF/IL-10 ratios. To gain insight into the cytokine production capacity and the cellular subsets involved, Ghanaian children with non-overlapping SMA or CM syndromes were recruited. Their $\mathrm{T}$ cell and monocyte activation statuses were compared. In addition, their intrinsic TNF and IL-10 secretion capacity was investigated using whole-blood stimulation assays with LPS and PHA, used as surrogate of monocyte and T cell stimulant, respectively. Similar analyses were performed on children with uncomplicated malaria (UM), considered as a control group for acute malaria and asymptomatic children (AC) living in the same area, recruited as a reference group for population baseline. The data show that the low IL-10 level in SMA cannot be attributed to a defective IL-10 response capacity and point to a specific dysregulation. Moreover, the parameters investigated provide interesting novel insights into the distinct inflammatory statuses in SMA and CM.

\section{Methods}

\section{Study site, patient recruitment and sample collection}

Venous blood was collected in sterile heparinised tubes from children (aged 1-12 years) enrolled at the Department of Child Health, Korle-Bu Teaching Hospital, Accra, during the peak malaria transmission season (July to August) in 2001 and 2003. Signed informed consent was obtained from the parents or guardians. The ethics and protocol review committee of the University of Ghana Medical School approved the study. Criteria for patient enrolment and classification have been detailed elsewhere [20]. Briefly, patients with asexual $P$. falciparum parasitaemia $\geq 5,000$ parasites $/ \mu \mathrm{L}$ of blood and axillary temperature $>37.5^{\circ} \mathrm{C}$ were further categorized into UM, SMA and CM. UM was defined as full consciousness, haemoglobin $(\mathrm{Hb}) \geq 8 \mathrm{~g} / \mathrm{dL}$, and no other complications of malaria. SMA patients had $\mathrm{Hb}$ levels $<5 \mathrm{~g} / \mathrm{dL}$, with full consciousness and no other known cause of anaemia. CM was defined as unrousable coma with a Blantyre coma score $\leq 3$ for more than an hour and without any sign of other possible causes of coma and $\mathrm{Hb}$ levels $\geq 5 \mathrm{~g} / \mathrm{dL}$. Children with a positive sickling test or any clinical presentation other than malaria were excluded from the study. Convulsing patients were excluded from the SMA and UM groups. Patients included in the study were followed up and blood samples were taken at 3 and 7 days post admission. Asymptomatic healthy children (AC) were recruited in Dodowa, a community nearby Accra, from a random sample of an existing cohort of pre-school and school children and matched for age and sex with the patients. $\mathrm{Hb}$ concentration and complete blood cell count were determined using an automated haematology analyzer (Sysmex). Parasitaemia was determined from Giemsastained thick and thin blood films and expressed as parasitized red cells per $\mu \mathrm{L}$ of blood, based on individual white blood cell counts as described [21]. As the patients recruited in 2001 and 2003 showed similar clinical, 
haematological and parasitical characteristics, the data were pooled.

\section{Flow cytometry}

Monocytes and $\mathrm{T}$ cells were identified on the basis of their forward/side scatter profiles and expression of CD14 (RM052, Immunotech) and CD3 (SK7, Becton Dickinson) respectively. Monocyte activation status was assessed by HLA-DR (L243, Becton Dickinson) surface expression as described [22]. CD69 (L78, Becton Dickinson) and HLA-DR expression was used to determine $\mathrm{T}$ cell activation [23]. Staining was conducted on whole blood using saturating amounts of fluorochrome-conjugated specific or control antibodies (Becton Dickinson) for 30 minutes at room temperature. Red blood cells were lysed, and white blood cells washed, fixed in $0.5 \%$ formaldehyde before acquisition within the next 24 hour on a FACScan flow cytometer (Becton Dickinson). A minimum of 5,000 positively-stained events were acquired. Staining was analysed using CellQuest 3.3 software (Becton Dickinson).

\section{Whole-blood stimulation}

Within four hours after venous blood collection, cytokine production was assessed following a 24-hour incubation of $500 \mu \mathrm{L}$ of heparinised whole blood with or without addition of $10 \mu \mathrm{l}$ of lipopolysaccharide (LPS, $E$. coli O111:B4; Sigma-Aldrich) or phytohaemagglutinin (PHA; Sigma-Aldrich) diluted in RPMI 1640 (Life technologies, Invitrogen) such that the final concentration was $100 \mathrm{ng} / \mathrm{mL}$ and $2 \mu \mathrm{g} / \mathrm{mL}$ for LPS and PHA respectively. Assays were conducted in polypropylene tubes in the presence of penicillin and streptomycin at $37^{\circ} \mathrm{C}$ in $5 \% \mathrm{CO}_{2}$. At the end of the incubation period, the samples were centrifuged and supernatants stored at $-80^{\circ} \mathrm{C}$ until cytokine assays. IL-10 and TNF levels released in the supernatant of un-stimulated whole-blood culture after 24-hour, reflect plasma concentrations at admission [21] and is referred as the "spontaneous cytokine secretion".

\section{Cytokine assays}

Concentrations of IL-10 and TNF in supernatant from whole blood assays were quantified in duplicate using commercially available ELISA kits (BioSource) according to the manufacturer's recommendations. Cytokine production capacity was calculated as the cytokine concentration measured in the supernatant of LPS or PHA stimulated whole blood divided by the concentration of cytokines produced in the un-stimulated condition i.e. the "spontaneous cytokine production" and reported as the fold-increase from the un-stimulated condition.

\section{Assessment of pigmented monocyte density}

Malaria pigment-containing monocyte densities were determined by counting 30 monocytes on thin films by an experienced haematologist blinded to clinical presentation and outcome, as described elsewhere [24].

\section{Statistical analyses}

Pearson-Chi-square test was used to compare qualitative data across groups. Quantitative data were compared across three or more groups by Kruskal-Wallis test, while the Mann-Whitney test was used for pairwise comparisons. $P$ values less than .05 were considered significant. Associations between different variables were analysed by Spearman's rank correlation and considered statistically significant if $\mathrm{r}>0.25$ and $P<.05$.

\section{Results}

Clinical, parasitological and haematological characteristics of malaria patients

The clinical, parasitological and haematological characteristics of the three groups of malaria patients at admission are shown in Table 1. Age, gender, parasitaemia, leukocyte and monocyte counts did not differ between groups. Lymphocyte counts were not significantly different in SMA and CM patients and both severe groups had higher counts than UM patients $(P \leq .0051)$. As expected, erythrocyte counts were lower in SMA than in CM or UM $(P \leq .0001)$. The percentage of circulating pigmented monocytes differed between the three groups, being lower in SMA than in CM $(P=.032)$, but higher than in UM $(P=.039)$ (Table 1$)$.

\section{SMA and CM cases show a similar transient monocyte deactivation phenotype independent of the number of pigmented monocytes}

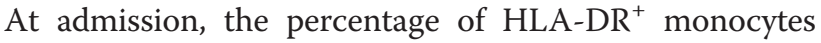
and the mean fluorescence intensity (MFI) of HLA-DR expression on monocytes were similar in SMA and CM patients $(P=.99)$. Both parameters were higher in UM patients $(P \leq .0001)$ and did not differ from AC children $(P \geq .56)$ (Figure $1 \mathrm{~A}$ and $\mathrm{B})$. The percentages of HLA-DR ${ }^{+}$ monocytes of SMA $(95.9 \pm 7.5)$ and CM $(94.6 \pm 11.7)$ patients as well as their HLA-DR MFI (SMA: $155.2 \pm 114.4$; CM: $147.8 \pm 77.4$ ) returned to levels similar to those of AC children 3 days post-admission $(P \geq .23)$.

Since haemozoin phagocytosis was shown to decrease monocyte HLA-DR surface expression [25], the association of monocyte HLA-DR expression with the number of circulating haemozoin-containing (pigmented) monocytes at admission was investigated. In all three clinical groups, the monocyte HLA-DR MFI was unrelated to the percentage of pigmented monocytes (SMA: $P=.26$; CM: $P=.92$; UM: $P=.69$ ), which did not correlate with 
Table 1 Clinical and biological parameters of Patients characteristics

\begin{tabular}{|c|c|c|c|c|c|}
\hline & SMA & CM & UM & $P$ value & $P$ value \\
\hline & & & & $\overline{\text { SMA vs. CM (1) }}$ & SMA vs. CM vs. UM (2) \\
\hline No. children & 108 & 144 & 80 & & \\
\hline Age (years) & $3.5(1-5)$ & $3.1(1-6)$ & $3.8(2-6)$ & $N S^{b}$ & $N S^{b}$ \\
\hline \multicolumn{6}{|l|}{$\operatorname{Sex}[n(\%)]$} \\
\hline Male & $59(54.6)$ & $78(54.2)$ & $44(55)$ & $N S^{a}$ & $N S^{a}$ \\
\hline Female & 49 (45.4) & $66(45.8)$ & $36(45)$ & $N S^{a}$ & $N S^{a}$ \\
\hline $\mathrm{Hb}(\mathrm{g} / \mathrm{dL})$ & $4.3(3.7-4.7)$ & $6.3(5-8.02)$ & $9.6(8.4-10.9)$ & $=.0001$ & $\leq .0001$ \\
\hline $\operatorname{RBC}\left(10^{9} / \mu \mathrm{L}\right)$ & $1.77(1.5-2)$ & $2.73(2.2-3.3)$ & $3.9(3.6-4.2)$ & $=.0001$ & $\leq .078$ \\
\hline WBC $\left(10^{6} / \mu \mathrm{L}\right)$ & $12.1(8.5-19.1)$ & $11.4(8.3-15.5)$ & $12.4(8-15.6)$ & $N S^{b}$ & $N S^{b}$ \\
\hline Lymphocyte $\left(10^{6} / \mu \mathrm{L}\right)$ & $5.3(2.9-8.1)$ & $3(1.8-4.8)$ & $1.9(1.5-3.3)$ & $N S^{b}$ & $\leq .0051$ \\
\hline Monocytes $\left(10^{6} / \mu \mathrm{L}\right)$ & $0.6(0.3-1.2)$ & $0.5(0.2-0.9)$ & $0.7(0.5-0.9)$ & $N S^{b}$ & $N S^{b}$ \\
\hline Parasitaemia & $41322(5060-989003)$ & $52356(5676-1872368)$ & $61000(7396-434024)$ & $N S^{b}$ & $N S^{b}$ \\
\hline HCM (\%) & $3.3(0-10)$ & $10(0-20)$ & $0(0-3.3)$ & $=.032$ & $\leq .039$ \\
\hline
\end{tabular}

Values given are medians numbers $\left(25^{\text {th }}-75^{\text {th }}\right.$ percentiles) except when indicated otherwise and for parasitaemia [geometric mean (range)]. CM, SMA, UM and AC refer to cerebral malaria, severe malarial anaemia, uncomplicated malaria and asymptomatic controls, respectively. $\mathrm{HCM}=$ haemozoin-containing monocytes.

(1) Comparison between SMA and CM.

(2) Comparison between the three groups SMA, CM and UM.

a Statistical significance was obtained using the chi-square test.

b Statistical significance was obtained using the using Mann-Whitney's test (1) or Kruskal-Wallis' test (2).

parasitaemia (SMA: $P=.94$; $\mathrm{CM}: P=.71$; UM: $P=.72$ ). Of note, the number of pigmented monocytes was associated neither with parasitaemia nor with $\mathrm{Hb}$ concentration.

\section{SMA and CM patients have similar early and late T cell activation markers expression profiles}

Because the time between infection and hospital admission - and hence duration of the ongoing infection may vary across malaria patients, their $\mathrm{T}$ cell activation status was assessed using early and late $\mathrm{T}$ cell activation markers, namely CD69 and HLA-DR, respectively (Figure 1C). SMA and CM patients had comparable percentages of early and late activated $\mathrm{T}$ cells (CD69: $P=.066$; HLA-DR: $P=.87$ ) and similar $\mathrm{T}$ cell MFI for these markers were observed in both groups (for CD69: SMA: $26.5 \pm 15.6$; CM: $21.9 \pm 10.4, P=.15$ ); for HLA-DR: SMA: $64.1 \pm 42.1$; CM: $42.3 \pm 24.6, P=.54)$. The percentages of early and late activated $\mathrm{T}$ cells in SMA or CM did not differ from UM patients (CD69: $P \geq .22$; HLA-DR: $P \geq .71$ ). However, malaria patients had higher percentages of early and late activated $\mathrm{T}$ cells than $\mathrm{AC}$ (CD69, $P \leq .0001$; HLA-DR, $P \leq .0003$ ).

\section{SMA patients show a lower acute phase IL-10 production compared to $\mathrm{CM}$ patients}

IL-10 and TNF levels spontaneously released during a 24-hour un-stimulated whole-blood culture, which reflect plasma concentrations at admission [21], showed much lower IL-10 levels in SMA compared to CM $(P=.003)$, whereas TNF levels were not different in both clinical groups $(P=.40)$ (Table 2). Consequently, the TNF/IL-10 ratio at admission was higher in SMA than in $\mathrm{CM}$ (median $=8.46\left[25^{\text {th }}\right.$ percentile $=2.23 ; 75^{\text {th }}$ percentile $=23]$ vs. 2.13 [0.26-14.6], $P=.015)$. IL-10 levels in SMA were lower than in UM patients $(P=.004)$ and not different from those of AC children $(P=.45)$. TNF levels in SMA and CM were comparable to UM $(P=.40)$, the lowest levels being in $\mathrm{AC}$ children (AC vs. SMA: $P=.03$; vs. CM: $P=.018$; vs. UM: $P=.003)$.

The spontaneous IL-10 production levels correlated neither with monocyte HLA-DR MFI nor with the percentage of pigmented monocytes in each of the SMA, CM, UM groups or when considering all malaria cases as a single group $(P \geq .18)$.

\section{SMA patients show a higher IL-10 and TNF monocyte production capacity than CM cases}

In order to determine whether the marked difference in the spontaneous IL-10 production between SMA and CM was linked to a monocyte IL-10 production defect, whole blood LPS stimulation was performed, as it primarily assesses monocyte responses [26]. After 24 hours, IL-10 levels were measured along with TNF levels (Table 2) and fold increases from spontaneous levels calculated (Figure 2). After LPS stimulation, IL-10 and TNF production increased in all groups, including in SMA patients.

Interestingly, the fold (relative) increase in IL-10 production observed in SMA was higher than in CM $(P=.0082)$, and not significantly different from the UM $(P=.09)$ and AC $(P=.06)$ groups (Figure 2$)$. 


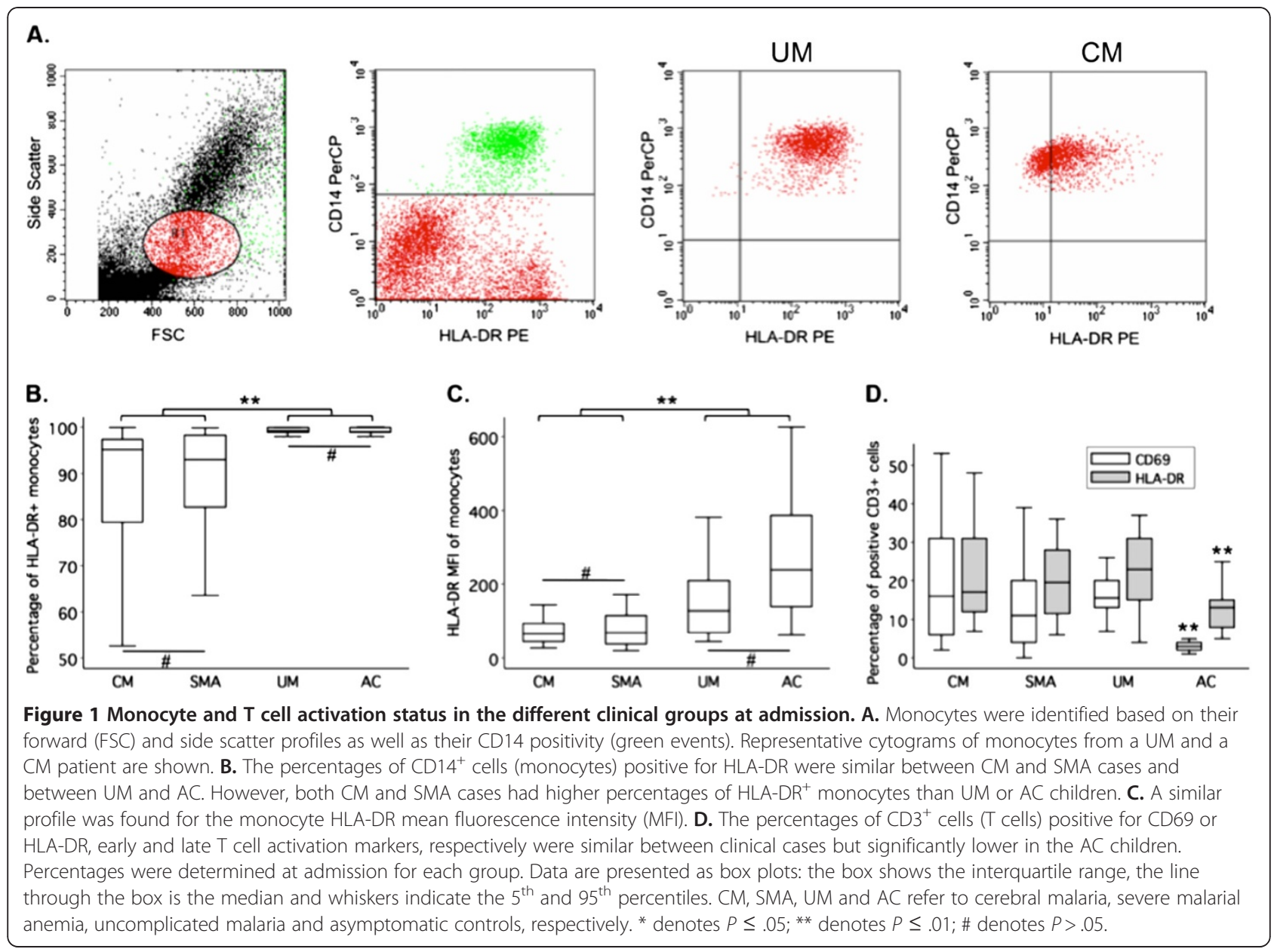

However, the absolute IL-10 levels reached after LPS stimulation in SMA were lower than in CM $(P=.013)$ but comparable to UM $(P=.52)$ (Table 2). All malaria patients produced higher IL-10 absolute levels than AC $(P \leq .0038)$.

The fold increase in LPS-stimulated TNF production was much higher in SMA than in CM $(P=.019)$, UM $(P=.04)$ or AC $(P=.02)$ (Figure 2$)$ and the absolute TNF levels reached after LPS stimulation were much higher in SMA than in CM $(P=.0055)$ and not significantly different from $\mathrm{UM}(P=.26)$ and $\mathrm{AC}(P=.43)$ (Table 2$)$.

\section{Low IL-10 T cell response in SMA}

To address the possible involvement of $\mathrm{T}$ cells in the specific cytokine imbalance observed in SMA, IL-10 and TNF levels were measured after stimulation with the

Table 2 Spontaneous and stimulated IL-10 and TNF production in malaria patients

\begin{tabular}{|c|c|c|c|c|}
\hline & & Spontaneous & LPS-stimulated & PHA-stimulated \\
\hline \multirow[t]{4}{*}{ IL-10 } & SMA & $24.3(11-39.6)$ & $188.8(70-342)$ & $55.3(30.8-176.6)$ \\
\hline & $\overline{C M}$ & $201.5(39-744.8)$ & $623.4(521.1-1028.25)$ & $608.9(148.05-725.25)$ \\
\hline & $\overline{U M}$ & $100(22.4-323.2)$ & $198.2(140.6-349.8)$ & $310(125.3-494.4)$ \\
\hline & $\overline{A C}$ & $12.6(5.7-17.4)$ & $25.8(5.1-406)$ & $588.4(434.2-811)$ \\
\hline \multirow[t]{4}{*}{$\overline{T N F}$} & SMA & $71.1(24.2-181)$ & $2196(1595.5-3025.5)$ & $2219(929.5-3606)$ \\
\hline & $\overline{C M}$ & $192.4(91.5-366.1)$ & $425.6(217.3-513.7)$ & $876.2(366.4-1514.5)$ \\
\hline & $\overline{U M}$ & $72.6(42.9-105.2)$ & $1344(388.2-2461)$ & $1352(703.7-2534.5)$ \\
\hline & $\overline{A C}$ & $55.5(16.3-94.7)$ & $1265(544.8-4435)$ & 5857 (2437-9203) \\
\hline
\end{tabular}

IL-10 and TNF levels were measured by ELISA in the supernatant of un-stimulated whole-blood (spontaneous production) or after LPS or PHA stimulation as described in Methods. Data are presented as median and interquartile range in pg/mL. CM, SMA, UM and AC refer to cerebral malaria, severe malarial anaemia, uncomplicated malaria and asymptomatic controls, respectively. 


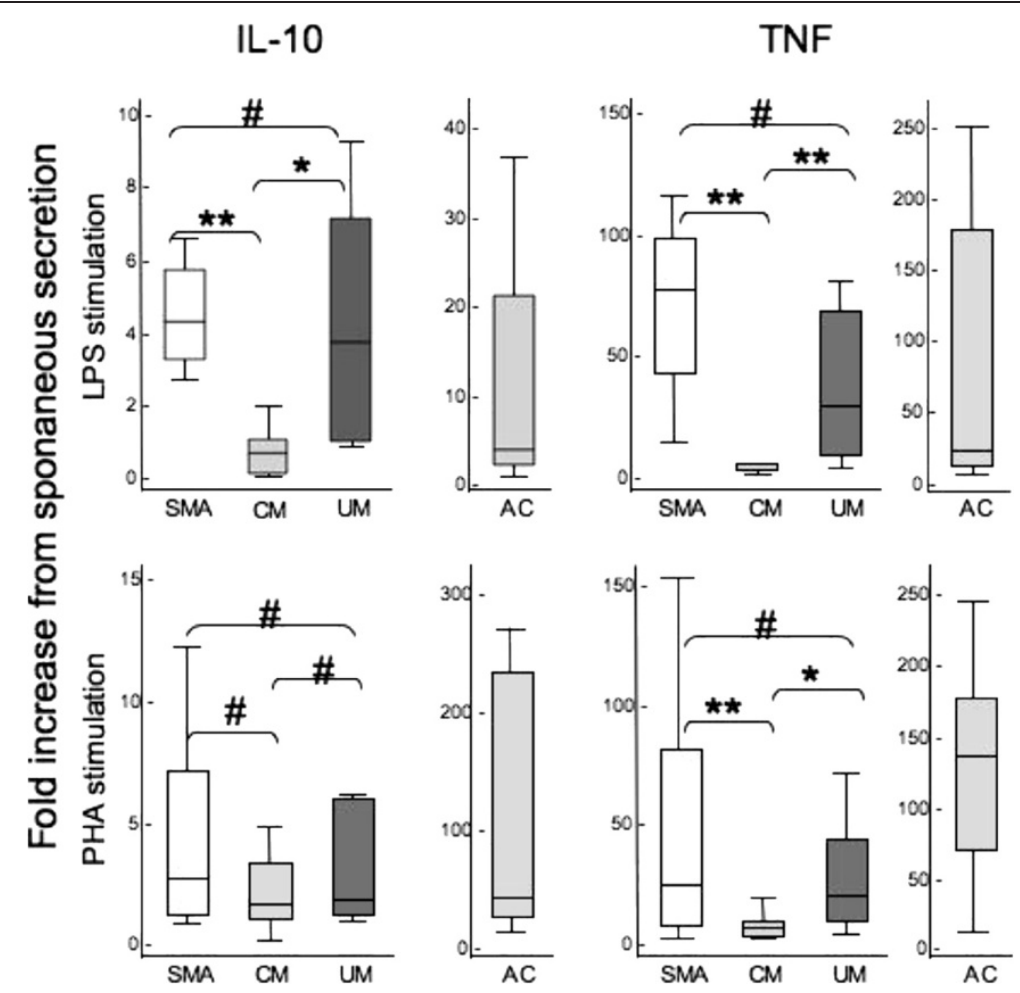

Figure 2 IL-10 and TNF production capacity in malaria patients. The IL-10 and TNF production capacity were measured after LPS and PHA stimulation as described in Methods. Fold increases from spontaneous cytokine secretion i.e. un-stimulated samples are presented as box plots: the box shows the interquartile range, the line through the box is the median and whiskers indicate the $5^{\text {th }}$ and $95^{\text {th }}$ percentiles. Statistical significance was determined by Mann-Whitney test. * denotes $P \leq .05$; ** denotes $P \leq .01$; \# denotes $P>05$.

mitogen PHA, which in these conditions stimulates primarily $\mathrm{T}$ cells, with little activation of monocytes [27]. PHA stimulation increased IL-10 and TNF production in all four groups of children (Table 2).

The PHA-stimulated fold-increase in IL-10 production in the SMA group was similar to that of $\mathrm{CM}(P=.18)$ and UM $(P=.35)$, but substantially lower than AC $(P=.0004)$ (Figure 2$)$. The absolute IL-10 levels reached after PHA stimulation were lower in SMA than in CM $(P=.0053)$, UM $(P=.036)$ or AC $(P=.0007)$ (Table 2$)$. In contrast, the fold-increase in TNF production was higher in SMA than in CM $(P=.01)$, and similar to UM $(P=.82)$ (Figure 2). The TNF absolute levels were higher in SMA than in CM $(P=.0008)$ or UM $(P=.036)$ (Table 2).

\section{Discussion}

The high TNF/IL-10 ratio observed in SMA suggests an imbalanced production of inflammatory cytokines that could contribute to anaemia $[5,6]$. Whether such an imbalance is an intrinsic characteristic of children with SMA or reflects a specific response pattern to malaria infection involving particular cellular sources has profound implications on the design of intervention strategies to prevent SMA. The data reported here show that
SMA patients indeed displayed low spontaneous IL-10 production at admission resulting in higher TNF/IL-10 ratios than $\mathrm{CM}$ cases. These findings are consistent with previous studies in Ghana [5,21], but also more recent studies in Southern Zambia [28]. Interestingly, in response to a monocyte or T cell stimulus IL-10 production readily increased in both CM and SMA patients, but SMA patients were characterized by a much higher amplitude of the IL-10 and TNF monocyte response to LPS compared to CM, possibly reflecting different monocyte priming status. However, the absolute levels of IL-10 reached after PHA-stimulation remained modest, much lower than for CM or any other group. This indicates that children experiencing SMA have no inherent incapacity to produce IL-10 and therefore that the imbalanced cytokine response at admission and upon further stimulation in vitro likely reflects a specific immunological pattern rather than an intrinsic predisposition to a deficient IL10-production.

The data also provide interesting insights into the immune status of children with CM. Although expression levels of surface activation markers on both lymphocytes and monocytes were similar in CM and SMA, CM patients presented a distinct cytokine expression profile, characterized by spontaneous production of high levels 
of both TNF and IL-10 but limited increase in TNF production after monocyte or $\mathrm{T}$ cell stimulation, suggesting an overall relative low-responsiveness to further stimulation. This points to a distinct functional status of circulating $\mathrm{T}$ cells and monocytes in SMA and CM, which both differed from the functional status in UM.

UM children had lower lymphocyte counts, limited monocyte deactivation, balanced IL-10 and TNF levels at admission (both lower than CM, IL-10 higher than SMA) and strong responsiveness to monocyte and $\mathrm{T}$ cell stimulation. Thus, based on analysis of circulating cells, the three clinical groups had specific response profiles to the ongoing infection and to further monocyte or $\mathrm{T}$ cell stimulation. IL-10 and TNF responses to a T cell stimulus were higher in $\mathrm{AC}$ than in any of the three clinical malaria groups, suggesting an impaired $\mathrm{T}$ cell responsiveness in malaria (regardless of the clinical presentation) as observed by others [29]. Parasite-related factors may explain the specific IL-10 production profile of SMA patients. Some studies [30,31] but not others [32] have found that haemozoin phagocytosis triggered the production of IL-10 by monocytes and induced a state of monocyte "anergy/reprogramming" associated with a deregulated production of pro-inflammatory cytokines such as TNF [33,34]. However, the lack of association of IL-10 plasma levels with the number of circulating haemozoin-containing monocytes observed here, including in CM patients who have the highest IL-10 levels, does not support a direct impact of haemozoin load on IL-10 production by circulating leukocytes.

There was no significant correlation between the number of pigmented monocytes and haemoglobin. This contrast with results from Casals-Pascual et al., although they found a moderately positive correlation $\left(\mathrm{r}^{2}=0,29\right)$ [35]. This reflects the unclear relationship between pigmented leukocytes and the disease manifestation or the parasite biomass. The number of circulating pigmented monocytes depends on a complex clearance kinetics [36], which may differ depending on whether anaemia is consecutive to an acute infection or results from a protracted infection.

CD36-dependent adhesion of infected erythrocytes to monocytes may modulate the inflammatory cytokine secretion profile, including IL-10 production [37-39] and the low IL-10 plasma levels in SMA patients may reflect the low CD36-binding capacity of their infected erythrocytes [40]. This is supported by the lower proportion of haemozoin-containing monocytes in SMA relative to $\mathrm{CM}$ patients, possibly reflecting the reduced phagocytosis of infected erythrocyte subsequent to CD36 binding [41] but may also merely reflect differences in parasite biomass.

The discrepant IL-10 levels in SMA and CM could result from different types or proportions of IL-10 producing cells. Recent studies suggest that various subsets of $\mathrm{CD}^{+} \mathrm{T}$ cells including $\mathrm{Tr} 1$ and $\mathrm{Th} 1$ are important contributors [42,43]. Compared to CM and UM, SMA cases produced lower absolute levels of IL-10 but higher levels of TNF in response to $\mathrm{T}$ cell stimulation. This suggests a $\mathrm{T}$ cell functional impairment specific for IL-10 production in children with SMA. Whether this reflects an infection-related cytokine expression programming or an effector/regulatory $\mathrm{T}$ cell subset imbalance is unclear. Additional work is needed to elucidate this question, especially since depletion of CD4+ T cells significantly alleviates anaemia in a murine model [44].

Beside T cells, two monocyte subpopulations with different IL-10 producing capacity upon LPS stimulation are now recognized: the regular $\mathrm{CD} 14^{\text {bright }} \mathrm{CD} 16^{-/ \text {dull }}$ monocytes producing both TNF and IL-10 and the CD14 ${ }^{\text {dim }} \mathrm{CD} 16^{\text {bright }}$ monocytes producing high levels of TNF and little or no IL-10 [45]. Although the latter subset was recently found to be enriched in SMA children [46], comparable CD14/CD16 cytograms and monocyte CD14 MFI (CM: 234.1 \pm 262.3 ; SMA: 162 \pm 95 ) and CD16 MFI (CM: $10.8 \pm 12.2$; SMA: $13.9 \pm 12.1)$ were observed here.

A significant but transient down-regulation of HLADR expression of circulating monocytes was observed in children with severe malaria, irrespective of the clinical form (SMA or CM). HLA-DR down-regulation has been described for dendritic cells in Kenyan children with acute malaria, but was observed in both mild and severe cases [47]. Phagocytosis of haemozoin and exposure to IL-10 both induce down-regulation of monocyte HLADR surface expression $[25,48]$. However, in the CM and SMA patients studied here, HLA-DR expression was independent from the number of pigmented monocytes and did not correlate with circulating IL-10 levels. The observed HLA-DR down-regulation rather results from the complex integration of multiple anti-inflammatory signals, as observed in severe inflammatory syndromes where it is generally associated with an impaired TNF production capacity in response to further LPS stimulation [49] reflecting a general cellular reprogramming phenomenon of acute inflammatory injuries [50-52]. The impaired TNF production after LPS stimulation observed in CM, but not in SMA, is reminiscent of this cellular reprogramming and suggests interference between the monocyte signalling pathway involved in the overwhelming cytokine production associated with CM and the LPS-triggered MD2 signalling pathway [53,54]. Thus, CM appears as an acute inflammatory syndrome with excessive TNF production by monocytes/macrophages rapidly inducing a high counter-regulatory IL-10 production. In contrast, the high TNF levels observed in SMA would result from a more chronic/sustained production of TNF maintained by an impaired IL-10 regulatory 
feedback reflecting a specific leukocyte polarization/ programming state in SMA.

\section{Conclusion}

The data reported here point towards a specific programming of monocytes and $\mathrm{T}$ cells in SMA patients where low IL-10 levels are not due to intrinsic production incapacity but rather to a specific polarization/ programming pathway. Differences in the environmental context as well as the intensity and duration of malariaassociated inflammatory stimuli may explain this specific cytokine response. Directions for future work include identification of the parasite factors implicated in the polarization of the immune response and ex vivo dynamic functional analysis of specific $\mathrm{T}$ cell subsets in children with CM or SMA. Dissecting the infectionacquired changes in cytokine expression profiles associated with SMA and exploring additional upstream and downstream mediators as well as cells possibly implicated in dyserythropoiesis or erythrophagocytosis is of major interest to design intervention strategies.

\section{Competing interest}

The authors have no conflict of interest. Jørgen Kurtzhals has received project funding for unrelated studies from Vifor Pharma, Switzerland and Novo Nordisk, Denmark.

\section{Authors' contributions}

$B G, J K, B D A$, $L H$ and $C B$ designed the study. GOA, BG and JK recruited the participants. PB, SL, GAA, JT and MMA generated the data. PB, OMP and CB analysed the data and wrote the manuscript. $C B$ supervised the research and secured the funding. All authors approved the final version of the manuscript.

\section{Acknowledgments}

The authors are grateful to the mothers and guardians who agreed to their children participating in the study. The authors thank the laboratory, medical and nursing staff of the Korle-Bu Teaching Hospital and the field and laboratory staff of NMIMR; C. Rogier for his statistical support; J-F Moreau, J. Dechanet-Merville, M. Mamani-Matsuda and S. J. Rogerson for helpful discussions.

Financial support was provided by the European programs INCO-DC (grant $\mathrm{n}^{\circ}$ IC18-CT-980370), the WHO/TDR/MIM project 980037, the Enhancement of Research Capacity in Developing Countries (ENRECA) program of the Danish International Development Assistance (Danida), grant n 14.Dan.8.L.306 and the PAL + program from the French Ministry of Research and Technology. This work is also part of the activities of the EviMalaR European Network of Excellence supported by the 7th European Framework Program (FP7/2007-2013, contract $N^{\circ}$ 242095). PB was supported by a fellowship from the Caisse Nationale d'Assurances Maladies, France.

\footnotetext{
Author details

'Institut Pasteur, Unité d'Immunologie Moléculaire des Parasites URA CNRS 2581, Paris, France. ${ }^{2}$ Immunology Department, Noguchi Memorial Institute for Medical Research, College of Health Sciences, University of Ghana, Accra, Ghana. ${ }^{3}$ Department of Hematology, School of Allied Health Sciences, College of Health Sciences, University of Ghana, Accra, Ghana. ${ }^{4}$ Department of Child Health, University of Ghana Medical School, College of Health Sciences, University of Ghana, Legon, Accra, Ghana. ${ }^{5}$ Centre for Medical Parasitology, Copenhagen University Hospital (Rigshospitalet), Copenhagen, Denmark. ${ }^{6}$ Department of Clinical Microbiology, Copenhagen University Hospital (Rigshospitalet), Copenhagen, Denmark. ${ }^{7}$ Department of Infectious Diseases, Copenhagen University Hospital (Rigshospitalet), Copenhagen, Denmark. ${ }^{8}$ Department of International Health, Immunology, and
}

Microbiology (ISIM), University of Copenhagen, Copenhagen, Denmark. ' UMR CNRS 5164, Bordeaux, France. ${ }^{10}$ Université de Bordeaux, Bordeaux, France.

Received: 16 January 2012 Accepted: 25 July 2012

Published: 1 August 2012

\section{References}

1. Breman JG: The ears of the hippopotamus: manifestations, determinants, and estimates of the malaria burden. Am J Trop Med Hyg 2001, 64:1-11.

2. Obonyo CO, Vulule J, Akhwale WS, Grobbee DE: In-hospital morbidity and mortality due to severe malarial anemia in western Kenya. Am J Trop Med Hyg 2007, 77:23-28.

3. Casals-Pascual C, Roberts DJ: Severe malarial anaemia. Curr Mol Med 2006, 6:155-168.

4. Haldar K, Mohandas N: Malaria, erythrocytic infection, and anemia. Hematology Am Soc Hematol Educ Program 2009:87-93.

5. Kurtzhals JAL, Adabayeri V, Quarm-Goka B, Akanmori BD, Oliver-Commey JO, Nkrumah FK, Behr C, Hviid L: Low plasma concentrations of interleukin 10 in severe malarial anaemia compared to cerebral and uncomplicated malaria. The Lancet 1998, 351:1768-1772.

6. Othoro C, Lal AA, Nahlen B, Koech D, Orago AS, Udhayakumar V: A low interleukin-10 tumor necrosis factor-alpha ratio is associated with malaria anemia in children residing in a holoendemic malaria region in western Kenya. J Infect Dis 1999, 179:279-282.

7. Linke A, Kuhn R, Muller W, Honarvar N, Li C, Langhorne J: Plasmodium chabaudi chabaudi: differential susceptibility of gene-targeted mice deficient in IL-10 to an erythrocytic-stage infection. Exp Parasitol 1996, 84:253-263.

8. Li C, Sanni LA, Omer F, Riley E, Langhorne J: Pathology of Plasmodium chabaudi chabaudi infection and mortality in interleukin-10-deficient mice are ameliorated by anti-tumor necrosis factor alpha and exacerbated by anti-transforming growth factor beta antibodies. Infect Immun 2003, 71:4850-4856.

9. Roodman GD: Mechanisms of erythroid suppression in the anemia of chronic disease. Blood Cells 1987, 13:171-184.

10. Means RT: Hepcidin and cytokines in anaemia. Hematology 2004 9:357-362.

11. Dufour C, Corcione A, Svahn J, Haupt R, Battilana N, Pistoia V: Interferon gamma and tumour necrosis factor alpha are overexpressed in bone marrow T lymphocytes from paediatric patients with aplastic anaemia. $\mathrm{Br}$ J Haematol 2001, 115:1023-1031.

12. Dufour C, Corcione A, Svahn J, Haupt R, Poggi V, Beka'ssy AN, Scime R, Pistorio A, Pistoia V: TNF-alpha and IFN-gamma are overexpressed in the bone marrow of Fanconi anemia patients and TNF-alpha suppresses erythropoiesis in vitro. Blood 2003, 102:2053-2059.

13. De Maria R, Zeuner A, Eramo A, Domenichelli C, Bonci D, Grignani F, Srinivasula SM, Alnemri ES, Testa U, Peschle C: Negative regulation of erythropoiesis by caspase-mediated cleavage of GATA-1. Nature 1999, 401:489-493.

14. Dai C, Chung IJ, Jiang S, Price JO, Krantz SB: Reduction of cell cycle progression in human erythroid progenitor cells treated with tumour necrosis factor alpha occurs with reduced CDK6 and is partially reversed by CDK6 transduction. Br J Haematol 2003, 121:919-927.

15. Chasis JA, Mohandas N: Erythroblastic islands: niches for erythropoiesis. Blood 2008, 112:470-478

16. Reibnegger G, Boonpucknavig V, Fuchs D, Hausen A, Schmutzard E, Wachter $\mathrm{H}$ : Urinary neopterin is elevated in patients with malaria. Trans $R$ Soc Trop Med Hyg 1984, 78:545-546.

17. Brown AE, Webster HK, Teja-Isavadharm P, Keeratithakul D: Macrophage activation in falciparum malaria as measured by neopterin and interferon-gamma. Clin Exp Immunol 1990, 82:97-101.

18. Biemba G, Gordeuk VR, Thuma PE, Mabeza GF, Weiss G: Prolonged macrophage activation and persistent anaemia in children with complicated malaria. Trop Med Int Health 1998, 3:60-65.

19. Waitumbi JN, Opollo MO, Muga RO, Misore AO, Stoute JA: Red cell surface changes and erythrophagocytosis in children with severe Plasmodium falciparum anemia. Blood 2000, 95:1481-1486

20. Kurtzhals JAL, Goka BQ, Akanmori BD, Hviid L: The importance of strict patient definitions in studies of malaria pathogenesis. Trends Parasitol 2001, 17:313-314 
21. Akanmori BD, Kurtzhals JAL, Goka BQ, Adabayeri V, Ofori MF, Nkruhma FK, Behr C, Hviid L: Distinct patterns of cytokine regulation in discrete clinical forms of $P$. falciparum malaria. Eur Cytokine Netw 2000, 11:113-118.

22. Hershman MJ, Cheadle WG, Wellhausen SR, Davidson PF, Polk HC: Monocyte HLA-DR antigen expression characterizes clinical outcome in the trauma patient. Br J Surg 1990, 77:204-207.

23. Ullman KS, Northrop JP, Verweij CJ, Crabtree GR: Transmission of signals from the lymphocyte antigen receptor to the genes responsible for cell proliferation and immune function: the missing link. Annu Rev Immunol 1990, 8:421-452.

24. Lyke KE, Diallo DA, Dicko A, Kone A, Coulibaly D, Guindo A, Cissoko Y, Sangare L, Coulibaly S, Dakouo B, Taylor TE, Doumbo OK, Plowe CV: Association of intraleukocytic Plasmodium falciparum malaria pigment with disease severity, clinical manifestations and prognosis in severe malaria. Am J Trop Med Hyg 2003, 69:253-259.

25. Schwarzer E, Alessio M, Ulliers D, Arese P: Phagocytosis of the malaria pigment, haemozoin, impairs expression of major histocompatibility complex class II antigen, CD54 and CD11C in human monocytes. Infect Immun 1998, 66:1601-1606.

26. Hermann C, von Aulock S, Graf K, Hartung T: A model of human whole blood lymphokine release for in vitro and ex vivo use. J Immunol Methods 2003, 275(1-2):69-79.

27. De Groote D, Zangerle PF, Gevaert Y, Fassotte MF, Beguin $Y$, Noizat-Pirenne F, Pirenne J, Gathy R, Lopez M, Dehart I, Igot D, Baudrihaye M, Delacroix D, Franchimont P: Direct stimulation of cytokines (IL1-b, TNF-a, IL-6, IFN-g and GM-CSF) in whole blood.I. Comparaison with isolated PBMC stimulation. Cytokine 1992, 4:239-248.

28. Thuma PE, van Dijk J, Bucala R, Debebe Z, Nekhai S, Kuddo T, Nouraie M, Weiss G, Gordeuk VR: Distinct clinical and immunologic profiles in severe malarial anemia and cerebral malaria in Zambia. J Infect Dis 2011, 203:211-219.

29. Riley EM, Andersson G, Otoo LN, Jepsen S, Greenwood BM: Cellular immune responses to Plasmodium falciparum antigens in Gambian children during and after an acute attack of falciparum malaria. Clin Exp Immunol 1988, 73:17-22.

30. Deshpande $P$, Shastry P: Modulation of cytokine profiles by malaria pigment-hemozoin: role of IL-10 in suppression of proliferative responses of mitogen stimulated human PBMC. Cytokine 2004, 28:205-213.

31. Keller CC, Yamo O, Ouma C, Ong'echa JM, Ounah D, Hittner JB, Vulule JM, Perkins DJ: Acquisition of hemozoin by monocytes down-regulates interleukin-12 p40 (IL-12p40) transcripts and circulating IL-12p70 through an IL-10-dependent mechanism: in vivo and in vitro findings in severe malarial anemia. Infect Immun 2006, 74:5249-5260.

32. Perkins DJ, Moore JM, Otieno J, Shi YP, Nahlen BL, Udhayakumar V, Lal AA In vivo acquisition of hemozoin by placental blood mononuclear cells suppresses PGE2, TNF-alpha, and IL-10. Biochem Biophys Res Commun 2003, 311:839-846.

33. Schwarzer E, Turrini F, Ulliers D, Giribaldi G, Ginsburg $H$, Arese P: Impairment of macrophage functions after ingestion of Plasmodium falciparum-infected erythrocytes or isolated malarial pigment. J Exp Med 1992, 176:1033-1041.

34. Schwarzer E, Skorokhod OA, Barrera V, Arese P: Hemozoin and the human monocyte-a brief review of their interactions. Parassitologia 2008, 50:143-145

35. Casals-Pascual C, Kai O, Cheung JO, Williams S, Lowe B, Nyanoti M, Williams TN, Maitland K, Molyneux M, Newton CR, Peshu N, Watt SM, Roberts DJ: Suppression of erythropoiesis in malarial anemia is associated with hemozoin in vitro and in vivo. Blood 2006, 108:2569-2577.

36. Day NP, Pham TD, Phan TL, Dinh XS, Pham PL, Ly VC, Tran TH, Nguyen TH, Bethell DB, Nguyan HP, Tran TH: Clearance kinetics of parasites and pigment-containing leucocytes in severe malaria. Blood 1996, 88:4694-4700

37. Urban $B C$, Willcox N, Roberts DJ: A role for CD36 in the regulation of the dendritic cell function. Proc Natl Acad Sci U S A 2001, 98:8750-8755.

38. Urban BC, Roberts DJ: Malaria, monocytes, macrophages and myeloid dendritic cells: sticking of infected erythrocytes switches off host cells. Curr Opin Immunol 2002, 14:458-465.

39. Urban BC, Cordery D, Shafi MJ, Bull PC, Newbold Cl, Williams TN, Marsh K: The frequency of BDCA3-positive dendritic cells is increased in the peripheral circulation of Kenyan children with severe malaria. Infect Immun 2006, 74:6700-6706.

40. Rogerson SJ, Tembenu R, Dobano C, Plitt S, Taylor TE, Molyneux ME: Cytoadherence characteristics of Plasmodium falciparum-infected erythrocytes from malawian children with severe and uncomplicated malaria. Am J Trop Med Hyg 1999, 61:467-472.

41. McGilvray ID, Serghides L, Kapus A, Rotstein OD, Kain KC: Nonopsonic monocyte/macrophage phagocytosis of Plasmodium falciparumparasitized erythrocytes: a role for CD36 in malarial clearance. Blood 2000, 96:3231-3240

42. Couper KN, Blount DG, Riley EM: IL-10: the master regulator of immunity to infection. J Immunol 2008, 180:5771-5777.

43. Couper KN, Blount DG, Wilson MS, Hafalla JC, Belkaid Y, Kamanaka M, Flavell RA, de Souza JB, Riley EM: IL-10 from CD4CD25Foxp3CD127 adaptive regulatory $T$ cells modulates parasite clearance and pathology during malaria infection. PLoS Pathog 2008, 4:e1000004.

44. Evans KJ, Hansen DS, van Rooijen N, Buckingham LA, Schofield L: Severe malarial anemia of low parasite burden in rodent models results from accelerated clearance of uninfected erythrocytes. Blood 2006, 107:1192-1199.

45. Ziegler-Heitbrock L: The CD14+ CD16+ blood monocytes: their role in infection and inflammation. J Leukoc Biol 2007, 81:584-592.

46. Ogonda LA, Orago AS, Otieno MF, Adhiambo C, Otieno W, Stoute JA: The levels of CD16/Fc gamma receptor IIIA on CD14+ CD16+ monocytes are higher in children with severe Plasmodium falciparum anemia than in children with cerebral or uncomplicated malaria. Infect Immun 2010, 78:2173-2181.

47. Urban BC, Mwangi T, Ross A, Kinyanjui S, Mosobo M, Kai O, Lowe B, Marsh K, Roberts DJ: Peripheral blood dendritic cells in children with acute Plasmodium falciparum malaria. Blood 2001, 98:2859-2861.

48. Fumeaux T, Pugin J: Role of interleukin-10 in the intracellular sequestration of human leukocyte antigen-DR in monocytes during septic shock. Am J Respir Crit Care Med 2002, 166:1475-1482.

49. Volk HD, Reinke P, Docke WD: Clinical aspects: from systemic inflammation to 'immunoparalysis'. Chem Immunol 2000, 74:162-177.

50. Cavaillon JM, Adrie C, Fitting C, Adib-Conquy M: Reprogramming of circulatory cells in sepsis and SIRS. J Endotoxin Res 2005, 11:311-320.

51. Cavaillon JM, Adib-Conquy M: Determining the degree of immunodysregulation in sepsis. Contrib Nephrol 2007, 156:101-111.

52. Biswas SK, Lopez-Collazo E: Endotoxin tolerance: new mechanisms, molecules and clinical significance. Trends Immunol 2009, 30:475-487.

53. Mockenhaupt FP, Cramer JP, Hamann L, Stegemann MS, Eckert J, Oh NR, Otchwemah RN, Dietz E, Ehrhardt S, Schroder NW, Bienzle U, Schumann RR: Toll-like receptor (TLR) polymorphisms in African children: Common TLR4 variants predispose to severe malaria. Proc Natl Acad Sci U S A 2006, 103:177-182.

54. McCall MB, Netea MG, Hermsen CC, Jansen T, Jacobs L, Golenbock D, van der Ven AJ, Sauerwein RW: Plasmodium falciparum infection causes proinflammatory priming of human TLR responses. J Immunol 2007 , 179:162-171.

doi:10.1186/1475-2875-11-253

Cite this article as: Boeuf et al:: Insights into deregulated TNF and IL-10 production in malaria: implications for understanding severe malarial anaemia. Malaria Journal 2012 11:253.

\section{Submit your next manuscript to BioMed Central and take full advantage of:}

- Convenient online submission

- Thorough peer review

- No space constraints or color figure charges

- Immediate publication on acceptance

- Inclusion in PubMed, CAS, Scopus and Google Scholar

- Research which is freely available for redistribution 